\title{
Emil Volek. Despistemes: La teoría literaria y cultural de Emil Volek. Una antología de textos. Andrés Pérez-Simón, ed. y trad. Madrid: Verbum, 2018.
}

El presente volumen recopila diferentes ensayos de Emil Volek, investigador de origen checo afincado en los EEUU desde los años setenta, donde ejerce como profesor de literatura latinoamericana y crítica literaria en Arizona State University. Editado por Andrés Pérez-Simón, profesor en la universidad de Cincinnati, quien también corre a cargo de las traducciones de algunos de los artículos, el libro no es sólo una excelente introducción al trabajo crítico de Volek, sino que puede leerse al mismo tiempo como un fascinante repaso a los debates que han definido los estudios culturales y la crítica literaria de los últimos ańos, especialmente en lo que concierne a la cultura latinoamericana estudiada desde la academia estadounidense. Es de encomiar, en este sentido, la labor del editor al conseguir que lo que es en un principio una colección de artículos posea una cohesión interna más propia de una monografía. Los artículos se agrupan en torno a dos ejes temáticos principales. La primera parte reúne ensayos que exploran aspectos que han marcado los estudios latinoamericanistas de las últimas décadas, mientras que la segunda parte se centra en consideraciones teóricas sobre literatura, cultura y estética. Ambas partes tienen en común la posición crítica e incómoda de Volek hacia la academia norteamericana, pese a que en cierto modo forme parte de ella.

En el trasfondo de Despistemes: La teoría literaria y cultural de Emil Volek late la noción de que la crítica literaria producida desde la universidad viene siempre influida por las teorías y los conceptos que son hegemónicos en ese momento y en ese espacio. El problema surge cuando estas influencias están más basadas en modas o en una búsqueda de lo último que en una verdadera superación o diálogo con la teoría anterior. Sarcásticamente, Volek afirma en un momento dado que «[e]n las humanidades, los paradigmas cambian con la misma frecuencia con la que cambia el parte meteorológico» (223). Una rápida consulta bibliográfica sobre lo que se ha escrito sobre
Borges, por ejemplo, a lo largo de las décadas es tanto una prueba de las variadas lecturas que se le puede dar a una obra (o en jerga académica, de la naturaleza polisémica de la literatura) como testamento de los cambios y ciclos que la crítica experimenta. En este sentido, a Emil Volek se le puede considerar un paleontólogo de la teoría literaria y cultural del siglo veinte, un excavador a contracorriente que muestra cómo las modas teóricas y disciplinares, en unos casos, o ciertas malinterpretaciones, asunciones o los mismos sesgos ideológicos que las rodean, en otros, condicionan la crítica y la recepción. La propia biografía de Volek informa, sin duda, su voluntad inquisitiva e historicista a la hora de problematizar los supuestos epistemes (o como él los llama con espíritu crítico, despistemes) que modulan la manera de pensar de la academia. Como indica Pérez-Simón en su introducción, el hecho de que la tesis doctoral de este sobre Alejo Carpentier fuera rechazada en Cuba por alejarse demasiado de la teoría marxista mientras que en el Chile de Pinochet era destruida por todo lo contrario ilustran de algún modo los vaivenes histórico-culturales y las improntas ideológicas que Volek explora en sus textos. Su proyecto de investigación, pues, orbita en torno a la necesidad de desideologizar la manera en que se estudia la cultura y la literatura. Como explica en un momento dado, a la hora de pensar críticamente, «[e]l problema de verdad aparece cuando las ideologías -incluyo aquí todas las Grandes Teorías - emborrona el objeto de estudio que se supone queremos estudiar y comprender» (148).

La primera parte del volumen comprende artículos que tienen como denominador común la cultura y literatura latinoamericana, concretamente la problematización de ciertas esencialidades asociadas a éstas y el papel que la academia ha tenido en perpetuar estos enfoques. A través del concepto de macondismo, acuñado por el sociólogo chileno José Joaquín Brunner, los tres primeros ensayos exploran 
cierta excepcionalidad latinoamericana, la que ofrece una visión de ésta permanentemente anclada en una especie de pre-modernidad mística, que ha sido producida y reproducida desde diferentes discursos hegemónicos y fundacionales. La extraordinaria capacidad de síntesis y voluntad historicista de Volek brillan en el ensayo «El camino de Macondo: América Latina entre la identidad cultural y los proyectos de modernización (meditaciones del bicentenario)» donde vincula el pensamiento macondista y sus ramificaciones culturales con los procesos históricos y políticos ocurridos en el continente desde el siglo XIX hasta el presente. Para Volek, si el siglo XIX latinoamericano «enarbola la bandera de la modernización como un ideal» (101), el siglo xx «da una vuelta de 180 grados» (104) y la crítica a la modernidad y el pensamiento conservador se afianzarán en el imaginario desde diferentes frentes y no siempre de modo evidente o debidamente contestado. Así, en otro de los ensayos de esta primera parte, el citadísimo texto de José Martí, «Nuestra América,» representa para Volek «un texto paradigmático del giro romántico, conservador y antimoderno, que el pensamiento hispanoamericano toma a finales del siglo XIX y que dará lugar a toda una secuela de reencarnaciones y consecuencias a lo largo del siglo XX» (81). La "retórica infantilista» (75) de liberación y modernización que Martí emplea para imaginar una nueva América nunca alcanzará una realización política, sino que se quedará en un "cuento de hadas» (75). Martí nunca ofrece una resolución clara a los distintos binomios de oposición que plantea y al final lastra la posibilidad de una modernización (de cambio) precisamente al insistir en una esencialidad latinoamericana (lo que la distingue de Europa/EEUU). Paradójicamente, pues, lo que pretende ser la visión de la creación de una nueva América se torna en la fundación de una ficción que mira al pasado y que nunca acabará de ser superada en todo el siglo xx. La inercia de caer en la esencialidad y de mirada hacia atrás es también la crítica que Volek realiza en su lectura de El laberinto de la soledad de Octavio Paz, incluida en el segundo ensayo en este volumen. De manera similar a lo que ocurría con Martí, el escritor mexicano acaba recurriendo al macondismo para explicar el fracaso de la modernidad en México, incidiendo en el binomio ellos/nosotros y concluyendo, de manera derrotista, que la entrada a la modernidad requería «un sacrificio: el de nosotros» (93).

En la discusión sobre América Latina y la modernidad, gran parte del problema reside en que en lugar de ser contestada o, al menos, problematizada, la excepcionalidad latinoamericana es muchas veces legitimada no sólo desde «dentro» (Martí, Paz), sino principalmente desde "fuera.» Así, Volek llama la atención sobre cómo la popularización del realismo mágico en el extranjero, por un lado, y el advenimiento de las teorías posmodernistas, por el otro, no han hecho sino celebrarlo: «El discurso posmodernista y el voyeurismo del Primer Mundo parecen ir de la mano, reforzando las posiciones esencialistas, fundamentalistas y oposicionales con respecto a la identidad latinoamericana» (89). En este sentido, es particularmente interesante el debate sobre el concepto de "testimonio" y la polémica que rodeó al libro de Rigoberta Menchú abordado en el ensayo «Ídolos rotos: los entramados ideológicos del Testimonio.» Aquí, Volek vuelve a demostrar su posicionamiento a contracorriente de lo "políticamente correcto" en la academia, al destapar las vergonzantes prácticas de encubrimiento ideológico que los latinoamericanistas pro-testimonio llevaron a cabo cuando el antropólogo David Stoll demostró las inconsistencias y falsedades de un texto (el de Menchú) que estaba siendo estudiado como "auténtico.» En el trasfondo del asunto, vuelve a asomar el fantasma de la excepcionalidad latinoamericana como algo que hay que proteger, aunque haya que inventarla o exagerarla. Volek resume cáusticamente la disposición de ciertos académicos al describirlos como «benévolos intelectuales que, desde su Primer Mundo, utilizan todas las artimañas del arsenal posmodernista poscolonial para 'defender' al subalterno, pareciera que a veces hasta de él mismo» (140). En la misma línea, los últimos tres ensayos de esta primera parte inciden en el papel, muchas veces nefasto, que las modas teóricas y disciplinares de las últimas décadas han tenido con respecto a los estudios literarios y culturales. Volek se despacha sobre todo con el posmodernismo y los estudios culturales. Con respecto a estos últimos lamenta que en los EE.UU. los estudios culturales perdieran el enfoque crítico original de la escuela de Birmingham influido por las ciencias sociales y el marxismo para convertirse en una especie de caricatura del «todo vale»: «[L]os estudios culturales posmo surgieron como una fiesta de aficionados en busca de lo que brillase como oro» (186). Volek critica cómo el relativismo posmoderno propició, entre otras cosas, una banalización de los textos culturales y de sus lecturas, algo que para el investigador checo «degrada y abarata la academia» (187).

La crítica a la academia norteamericana está también presente en los artículos de la segunda parte, cuyo contenido en general es más teórico, 
con ensayos dedicados a la filosofía del lenguaje y al estructuralismo de la Escuela de Praga. Aquí Volek hace gala de una visión más macro para explorar el origen del posestructuralismo tal y como se consolidó en la universidad estadounidense. Así, considera que el prefijo "pos» en el término es equívoco puesto que, en realidad, solo es posterior a un cierto estructuralismo, el francés, y omite el estructuralismo checo, anterior a éste y que además ya prefiguraba la crítica deconstructivista del lenguaje que Derrida popularizaría más tarde. Volek busca insertar el legado de la Escuela de Praga y de nombres como Mukarovsky, entre otros, en la discusión actual para intentar entender y tal vez desarrollar un nuevo paradigma "que nos permita superar los arruinados despistemes modernos y posmodernos» (208).

Este deseo de superación encierra dos razones que de alguna manera sintetizan y dan forma al pensamiento crítico de Volek que aparece a lo largo del libro. Por un lado, algo que parece obvio pero que no lo es tanto y que aparece de manera recurrente en los textos: la necesidad del investigador de leer y estudiar el pasado, de comprender que su objeto de estudio o el prisma teórico con el que lo analiza se puede trazar en la historia, descubriendo así los sesgos ideológicos o las omisiones que lo conforman. Por otro lado, y relacionado con esto, destaca la necesidad del investigador de ser independiente, algo difícil en ocasiones, cuando la burbuja académica puede aparecer cerrada y conservadora (tal vez no en el discurso, pero sí en las prácticas), negando o censurando aquello que no se ajusta a su despisteme actual. En definitiva, Despistemes: La teoría literaria y cultural de Emil Volek es un libro muy recomendable para entender los movimientos teóricos y debates que rodean al estudio de la literatura y cultura latinoamericana; por su posicionamiento crítico e incómodo con ciertas prácticas investigadoras es particularmente recomendable para aquellos que comienzan su andadura académica, no sólo porque resume con acierto lo que se ha venido cociendo en los departamentos de humanidades a nivel teórico en las últimas décadas, sino en especial porque ejemplifica un espíritu investigador independiente e inconformista necesario en la actualidad.

Vicent Moreno Arkansas State University 